\title{
An FGF8b-mimicking peptide with potent antiangiogenic activity
}

\author{
XIAOMIAN LIN ${ }^{1 *}$, LI SONG $^{1 *}$, DAN HE $^{1 *}$, XIANGFENG ZENG ${ }^{1}$, \\ JIANZHANG WU ${ }^{2}$, WU LUO ${ }^{1}$, QI YANG ${ }^{1}$, JZZHONG WANG ${ }^{1}$, TIANXIANG WANG ${ }^{1}$, \\ JIALONG CAI ${ }^{1}$, YANLING LIN ${ }^{1}$, FUBIN LAI ${ }^{1}$, WENTAO PENG ${ }^{1}$ and XIAOPING WU ${ }^{1,2}$ \\ ${ }^{1}$ Institute of Tissue Transplantation and Immunology, Key Laboratory of Functional Protein Research \\ of Guangdong Higher Education Institutes and Key Laboratory of Molecule Immunology and Antibody Engineering \\ of Guangdong Province, Jinan University, Guangzhou, Guangdong 510632; ${ }^{2}$ Department of Pharmacy, \\ School of Pharmaceutical Science, Wenzhou Medical University, Wenzhou, Zhejiang 325035, P.R. China
}

Received January 28, 2016; Accepted January 18, 2017

DOI: $10.3892 / \mathrm{mmr} .2017 .6651$

\begin{abstract}
Fibroblast growth factor (FGF) $8 b$ interacts with its receptors and promotes angiogenesis in hormone-dependent tumors. In the present study, we demonstrated that a short peptide, termed $8 \mathrm{~b}-13$, which mimics part of the FGF8b structure, significantly inhibited the proliferation and migration of human umbilical vein endothelial cells (HUVECs) triggered by FGF8b using 3-(4,5-dimethylthiazol-2-yl)-2,5-diphenyltetrazolium bromide (MTT), flow cytometry and an in vitro scratch assay. In addition, the findings from western blotting and reverse transcription-quantitative polymerase chain reaction revealed that 8b-13 appeared to counteract the effects of FGF8b on the expression of cyclin D1, the activation of signaling cascades, and the expression of proangiogenic factors; these actions may be involved in the mechanism underlying the inhibitory effects of 8b-13 on FGF8b-induced HUVEC proliferation and migration. The present results suggested that $8 \mathrm{~b}-13$ may be considered a potent FGF8b antagonist with antiangiogenic activity, and may have potential as a novel therapeutic agent for the treatment of cancer characterized by abnormal FGF8b upregulation.
\end{abstract}

\section{Introduction}

Fibroblast growth factor (FGF) 8 is a member of the FGF family. Based on sequence homology and phylogeny, FGF8

Correspondence to: Professor Xiaoping Wu, Institute of Tissue Transplantation and Immunology, Key Laboratory of Functional Protein Research of Guangdong Higher Education Institutes and Key Laboratory of Molecule Immunology and Antibody Engineering of Guangdong Province, Jinan University, 601 Huangpu Avenue, Guangzhou, Guangdong 510632, P.R. China

E-mail: twxp@jnu.edu.cn

*Contributed equally

Key words: FGF8b, antagonist peptide, proliferation, migration can be classified in the same subfamily as FGF17 and FGF18. Four FGF8 isoforms have been reported in humans, including $\mathrm{a}, \mathrm{b}$, e and $\mathrm{f}$, which are generated by alternative splicing of the FGF8 gene. Among them, FGF8b is the main isoform expressed in hormone-dependent tumors, where it displays the strongest mitogenic and angiogenic potential $(1,2)$. Previous studies have reported that FGF8b may facilitate the progression of reproductive cancers, including prostate, breast and ovarian cancer, through the stimulation of cellular proliferation and angiogenesis (3-5). Therefore, FGF8b is considered a potential target for the treatment of hormone-dependent tumors. In addition, the antitumor activity of a monoclonal anti-FGF8 antibody has been reported in FGF8b-expressing human prostate cancer xenografts $(6,7)$.

FGF8b binds to its receptor (FGFR) and its activation triggers intracellular signaling cascades that promote cellular proliferation and angiogenesis, which are involved in tumor progression (8). Based on structural data regarding the interaction of FGF8b with its receptor, the $\mathrm{gN}$ helix domain of FGF8b is responsible for the high affinity and specificity of the FGF8b-FGFR interaction. A short peptide $8 b-13$ mimicking the gN helix of FGF8b may inhibit the biological activity of FGF8b by disturbing the interaction between FGF8b and its receptors. Our previous study demonstrated that the $8 \mathrm{~b}-13$ peptide suppressed FGF8b-induced proliferation of human prostate cancer cells (9). FGF8b participates in autocrine cancer signaling by stimulating the proliferation of hormone-sensitive cancer cells that secrete it. In addition, it can also exert paracrine effects on vascular endothelial cells and promote angiogenesis. The present study aimed to evaluate the effect of the FGF8b-mimicking peptide $8 b-13$ on the angiogenic activity of FGF8b.

\section{Materials and methods}

Materials. Human recombinant FGF8b was purchased from PeproTech, Inc. (Rocky Hill, NJ, USA). Polyvinylidene difluoride membrane was purchased from EMD Millipore (Billerica, MA, USA). The enhanced chemiluminescence (ECL) detection kit was obtained from Thermo Fisher Scientific, 
Inc. (Waltham, MA, USA). Primary antibodies against the following proteins were purchased from Cell Signaling Technology, Inc. (Danvers, MA, USA): cyclin D1 mAb (cat. no. 2978), phosphorylated (p)-fibroblast growth factor receptor substrate (FRS) $2 \alpha$ (Tyr196) antibody (cat. no. 3864), extracellular signal-regulated kinase (Erk) $1 / 2 \mathrm{mAb}$ (cat. no. 4695), p-Erk1/2 (Thr202/Tyr204) mAb (cat. no. 4370), p38 MAPK antibody (cat. no. 9212), p-p38 (Thr180/Tyr182) mAb (cat. no. 4631), c-Jun N-terminal kinase (JNK) mAb (cat. no. 9258), p-JNK (T183/Y185) mAb (cat. no. 4671), Akt (pan) mAb (cat. no. 4691), p-Akt (Ser 473) mAb (cat. no. 4060), p-STAT5 (Tyr694) mAb (cat. no. 4322) and GAPDH mAb (cat. no. 2118). Horseradish peroxidase (HRP)-conjugated secondary antibodies (cat. no. 7074P2) were purchased from Cell Signaling Technology, Inc. The SYBR Green Q-PCR kit was obtained from Bio-Rad Laboratories, Inc. (Hercules, CA, USA). Human umbilical vein endothelial cells (HUVECs) obtained from the Institute of Tissue Transplantation and Immunology, Jinan University (Guangzhou, China) were cultured in Dulbecco's modified Eagle's medium (DMEM; Invitrogen; Thermo Fisher Scientific, Inc.) containing 10\% fetal bovine serum (FBS) and maintained in a humidified atmosphere containing $5 \% \mathrm{CO}_{2}$ at $37^{\circ} \mathrm{C}$. The $8 \mathrm{~b}-13$ peptide with a purity $>98 \%$ was synthesized by Beijing SBS Genetech, Co., Ltd. (Beijing, China).

Cell viability assay. HUVECs were seeded in 96-well plates at a density of $1 \times 10^{4}$ per well, and allowed to adhere overnight. Cells were cultured in DMEM supplemented with $0.4 \%$ FBS for $24 \mathrm{~h}$, and then treated with the following: 1, 5, 25, $125 \mathrm{nM} 8 \mathrm{~b}-13$ alone, $20 \mathrm{ng} / \mathrm{ml}$ FGF8b alone, or $20 \mathrm{ng} / \mathrm{ml}$ FGF8b preceded by treatment with $1,5,25,125 \mathrm{nM} 8 \mathrm{~b}-13$ for $5 \mathrm{~min}$ in a humidified atmosphere containing $5 \% \mathrm{CO}_{2}$ at $37^{\circ} \mathrm{C}$. After $48 \mathrm{~h}$, the number of viable cells was evaluated using the 3-(4,5-dimethylthiazol-2-yl)-2,5-diphenyltetrazolium bromide (MTT) assay. Briefly, $20 \mu \mathrm{l}$ of MTT $(5 \mathrm{mg} / \mathrm{ml})$ was added to each well, medium was discarded $4 \mathrm{~h}$ later and $100 \mu \mathrm{l}$ of dimethyl sulfoxide (DMSO) was added to each well. The plate was maintained at room temperature for $30 \mathrm{~min}$ and the absorbance was immediately measured at $570 \mathrm{~nm}$. The inhibition rate was calculated according to the following formula: Inhibition rate $(\%)=\left[\left(\mathrm{OD}_{(\mathrm{FGF} 8 \mathrm{~b})}-\mathrm{OD}_{(\mathrm{FG}}\right.\right.$ F8b+8b-13) $\left.) /\left(\mathrm{OD}_{(\mathrm{FGF} 8 \mathrm{~b})}-\mathrm{OD}_{\text {(control) }}\right)\right] \times 100 \%$. The control group cells did not receive FGF8b or $8 b-13$.

Cell cycle analysis. HUVECs were seeded in 12-well plates at a density of $1 \times 10^{5}$ cells per well, and allowed to adhere overnight. Cells were incubated for $24 \mathrm{~h}$ in DMEM supplemented with $0.4 \%$ FBS in a humidified atmosphere containing $5 \% \mathrm{CO}_{2}$ at $37^{\circ} \mathrm{C}$. Subsequently, cells were treated with $20 \mathrm{ng} / \mathrm{ml} \mathrm{FGF8b}$ alone, or $20 \mathrm{ng} / \mathrm{ml}$ FGF8b plus 1, 5, 25, $125 \mathrm{nM} 8 \mathrm{~b}-13$ at $37^{\circ} \mathrm{C}$ for $48 \mathrm{~h}$. The cells were then washed three times with cold PBS, trypsinized and centrifuged at $250 \mathrm{x} \mathrm{g}$ at $4^{\circ} \mathrm{C}$ for $10 \mathrm{~min}$. The pellets were resuspended in PBS containing 10\% FBS. Ice-cold $70 \%$ ethanol was added dropwise, the samples were maintained at $4^{\circ} \mathrm{C}$ for $30 \mathrm{~min}$, and were stained with propidium iodide (PI; Sigma-Aldrich; Merck Millipore, Darmstadt, Germany). Then cell cycle was analyzed by FACSCalibur-sort 4 (Becton Dickinson, Franklin Lakes, NJ, USA). The ModFit DNA analysis version 3.1 (Verity Software House, Topsham, ME, USA) was used to analyze the distribution of cells at various phases of the cell cycle.

Western blot analysis. HUVECs were seeded in 6-well plates at a density of $2 \times 10^{5}$ cells/well and allowed to adhere overnight. Cells were incubated for $24 \mathrm{~h}$ in DMEM supplemented with $0.4 \%$ FBS in a humidified atmosphere containing $5 \% \mathrm{CO}_{2}$ at $37^{\circ} \mathrm{C}$. Subsequently, cells were treated with $20 \mathrm{ng} / \mathrm{ml}$ FGF8b alone, $20 \mathrm{ng} / \mathrm{ml}$ FGF8b preceded by treatment with 1, 5, 25, $125 \mathrm{nM} 8 \mathrm{~b}-13$. HUVECs were collected and lysed in 1x SDS-PAGE loading buffer. The protein samples were then separated by $10 \%$ SDS-PAGE and transferred onto a polyvinylidene difluoride membrane. The membrane was blocked with $5 \%$ non-fat dry milk at room temperature for $1 \mathrm{~h}$, followed by incubation with the primary antibodies, including anti-cyclin D1 (1:2,000), anti-p-FRS2 $\alpha(1: 4,000)$, anti-Erk1/2 (1:4,000), anti-p-Erk1/2 (1:4,000), anti-p38 (1:4,000), anti-p-p38 (1:4,000), anti-JNK (1:4,000), anti-p-JNK $(1: 4,000)$, anti-Akt $(1: 4,000)$, anti-p-Akt $(1: 4,000)$ and anti-p-STAT5 $(1: 4,000)$ at $4^{\circ} \mathrm{C}$ overnight. The membrane was then probed with goat anti-rabbit HRP-conjugated immunoglobulin G $(1: 5,000)$ for $1 \mathrm{~h}$ at room temperature. The bands were visualized with ECL detection kit according to the manufacturer's protocol. GAPDH (1:4,000 dilution for anti-GAPDH antibody) was used as a loading control. The bands were analyzed by QuantityOne version 4.6.2 (Bio-Rad Laboratories, Inc., Hercules, CA, USA).

Analysis of cell migration by in vitro scratch assay. HUVEC cells $\left(1 \times 10^{5}\right)$ were incubated on 12 -well plates overnight, allowing cells to adhere and spread completely. A 'scratch' was created by scraping the cell monolayer in a straight line with a $10 \mu \mathrm{l}$ pipette tip. After three washes with PBS to remove debris, cells were maintained for $24 \mathrm{~h}$ in DMEM supplemented with $0.4 \% \mathrm{FBS}$, and subsequently treated with $20 \mathrm{ng} / \mathrm{ml}$ FGF8b alone, or $20 \mathrm{ng} / \mathrm{ml}$ FGF8b plus $25 \mathrm{nM}$ 8b-13. Photomicrographs were acquired using a phase-contrast microscope at the defined time points $(0,12,24$ and $48 \mathrm{~h}$ ). The Image Pro-Plus 6.0 software (Media Cybernetics, Inc., Rockville, MD, USA) was used for the quantitative analysis of the scratch distance. The migration distance was calculated according to the formula: Migration distance $=$ scratch distance $(0 \mathrm{~h})$-scratch distance (n h).

Reverse transcription-quantitative polymerase chain reaction (RT-qPCR). HUVECs cultured in DMEM supplemented with $0.4 \%$ FBS were treated with $20 \mathrm{ng} / \mathrm{ml} \mathrm{FGF8b}$ alone or $20 \mathrm{ng} / \mathrm{ml}$ FGF8b together with $25 \mathrm{nM} 8 \mathrm{~b}-13$ for $48 \mathrm{~h}$. Total RNA was extracted using TRIzol ${ }^{\circledR}$ (Invitrogen; Thermo Fisher Scientific, Inc.) according to the manufacturer's protocol. Total RNA $(1 \mu \mathrm{g})$ was reverse transcribed into cDNA using the RevertAid First Strand cDNA Synthesis kit (Bio-Rad Laboratories, Hercules, CA, USA). Briefly, $12 \mu \mathrm{l}$ mixture containing $1 \mu \mathrm{g}$ total RNA and $1 \mu \mathrm{l}$ oligo $(\mathrm{dT})_{18}$ primer was incubated at $65^{\circ} \mathrm{C}$ for $5 \mathrm{~min}$ prior to the addition of $4 \mu \mathrm{l}$ (5x reaction buffer), $1 \mu \mathrm{l}$ RiboLock RNase Inhibitor $(20 \mathrm{u} / \mu \mathrm{l}), 2 \mu \mathrm{l}(10 \mathrm{mM}) \mathrm{dNTP} \operatorname{mix}$ and $1 \mu \mathrm{l}$ RevertAid M-MuLV reverse transcriptase and incubation at $42^{\circ} \mathrm{C}$ for $1 \mathrm{~h}$. qPCR analysis was performed on cDNA using the SYBR Green Q-PCR kit (Bio-Rad Laboratories, Hercules, CA, USA). The qPCR reaction mixture contained $10 \mu 12 \mathrm{x}$ real-time PCR mix, $1 \mu$ l forward primer, $1 \mu \mathrm{l}$ reverse primer, $1 \mu \mathrm{l}$ cDNA 

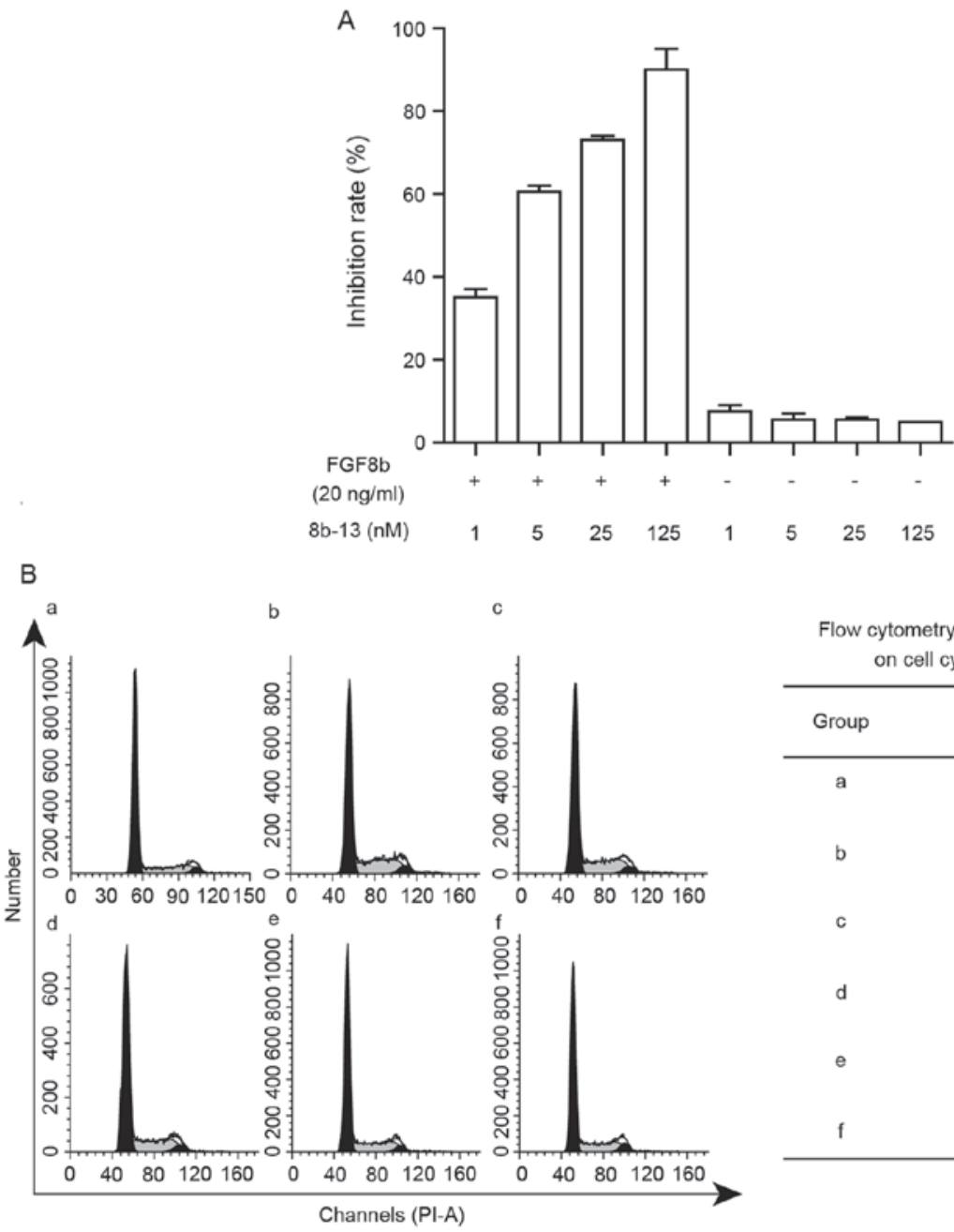

\begin{tabular}{|c|c|c|c|}
\hline Group & G0/G1 (\%) & G2/M (\%) & $\mathrm{S}(\%)$ \\
\hline a & $72.00 \pm 0.87$ & $4.56 \pm 1.41$ & $23.44 \pm 0.85$ \\
\hline b & $60.65 \pm 1.12^{\mathrm{w}}$ & $5.46 \pm 0.89$ & $33.89 \pm 0.68^{\mathrm{At \prime}}$ \\
\hline c & $63.21 \pm 0.80$ & $4.98 \pm 1.11$ & $31.81 \pm 1.01$ \\
\hline$d$ & $66.63 \pm 0.73^{*}$ & $4.55 \pm 0.68$ & $28.82 \pm 1.23^{*}$ \\
\hline e & $67.88 \pm 1.21^{*}$ & $4.20 \pm 1.05$ & $27.93 \pm 0.92^{*}$ \\
\hline$f$ & $66.39 \pm 0.78^{*}$ & $6.19 \pm 0.68$ & $27.42 \pm 1.05^{*}$ \\
\hline
\end{tabular}

C
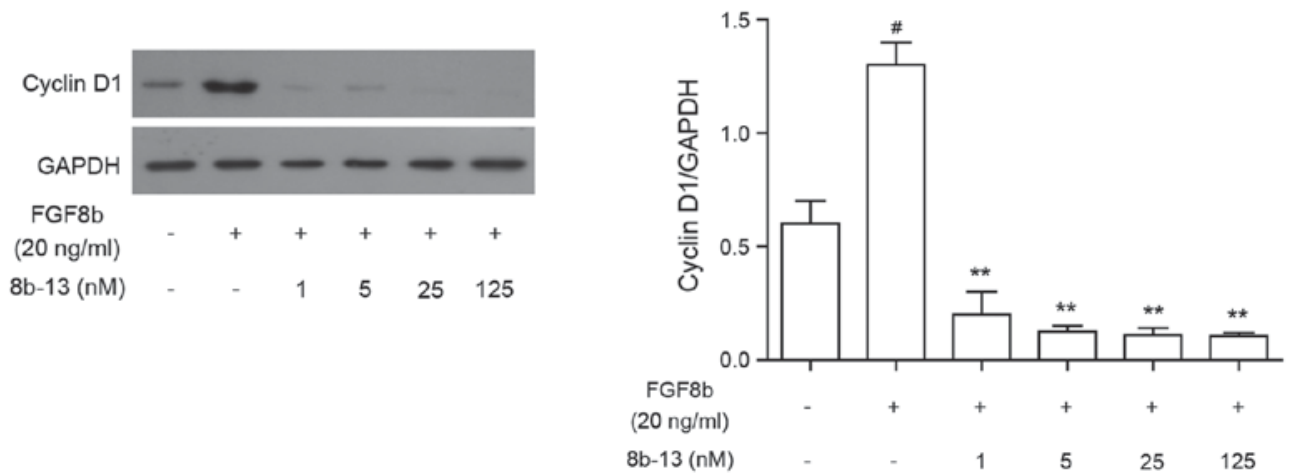

Figure 1. Effects of 8b-13 on the FGF8b-induced proliferation of HUVECs. (A) HUVECs were treated with 8b-13 alone, or 20 ng/ml FGF8b plus 8b-13 at the indicated concentrations. Cell viability was measured after $48 \mathrm{~h}$ using MTT assay. (B) Effects of 8b-13 on the cell cycle progression of FGF8b-stimulated HUVECs were assessed by PI staining combined with flow cytometry. HUVECs were starved in DMEM supplemented with $0.4 \%$ FBS for $24 \mathrm{~h}$ and treated with $20 \mathrm{ng} / \mathrm{ml} \mathrm{FGF8b}$ (Group b), or $20 \mathrm{ng} / \mathrm{ml}$ FGF8b plus increasing concentrations (1,5,25 and $125 \mathrm{nM}$ ) of 8b-13 (Groups c-f) for $48 \mathrm{~h}$. Control cells did not receive FGF8b or 8b-13 (Group a). (C) 8b-13 downregulated the expression of cyclin D1 in HUVECs. Starved cells were pretreated with 8b-13 at the indicated concentrations for $40 \mathrm{~min}$ prior to stimulation with $20 \mathrm{ng} / \mathrm{ml}$ FGF8b for $12 \mathrm{~h}$. Western blot analysis was performed using cell lysates and anti-cyclin D1 primary antibody. Data are expressed as the mean \pm standard deviation. Experiments were performed in triplicate. ${ }^{\#} \mathrm{P}<0.05,{ }^{\# \#} \mathrm{P}<0.01$ vs. control group; ${ }^{*} \mathrm{P}<0.05$, ${ }^{, * *} \mathrm{P}<0.01$ vs. FGF8b alone group. FGF, fibroblast growth factor; HUVEC, human umbilical vein endothelial cells; PI, propidium iodide.

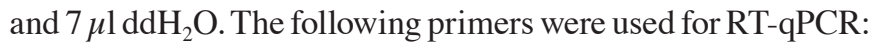
GAPDH, forward 5'-CCCACT CCTCCACCTTTGAC-3', reverse 5'-TGTGCTGTAGGAAGCTCA-3'; urokinasetype plasminogen activator (uPA), forward 5'-CGCAG TCACACCAAGGAAGAGAATG-3', reverse 5'-TCTGTGC AGAGCCTATCTTCCCAGT-3'; vascular endothelial growth factor (VEGF), forward 5'-GGCAGAATCATCACGAAG-3', reverse 5'-TGTGCTGTAGGAAGCTCA-3'; and matrix metalloproteinase-9 (MMP9), forward 5'-CAGAGATGCG TGGAGAGT-3' and reverse 5'-TCTTCCGAGTAGTTTTGG-3'. Amplification was performed using the CFX96 Touch Deep Well Real-Time PCR Detection system (Bio-Rad Laboratories, Inc.) under the following conditions: $95^{\circ} \mathrm{C}$ for $5 \mathrm{~min}, 95^{\circ} \mathrm{C}$ for $10 \mathrm{sec}, 59^{\circ} \mathrm{C}$ for $5 \mathrm{sec}$ for 40 cycles, $95^{\circ} \mathrm{C}$ for $10 \mathrm{sec}$, melt 

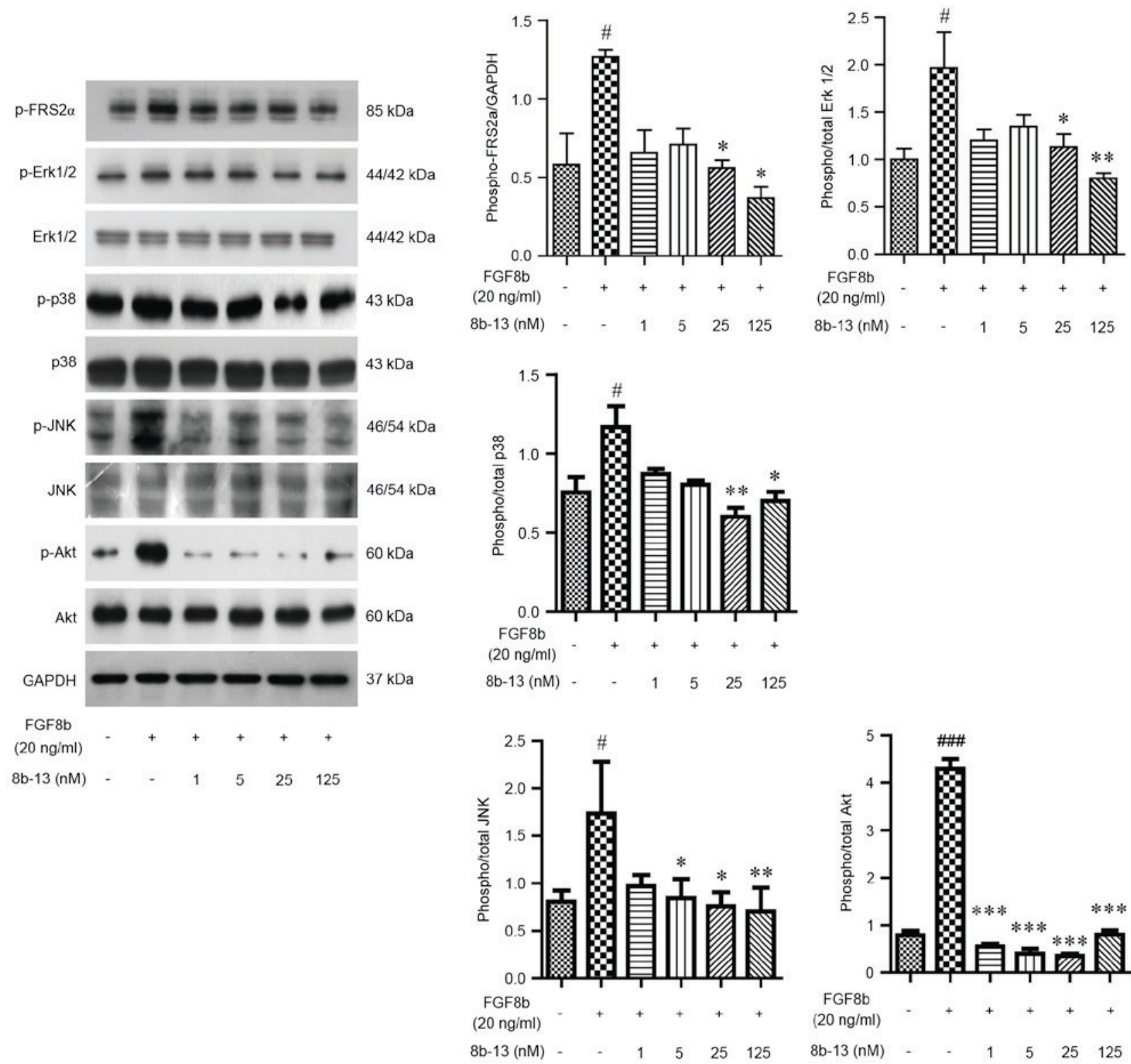

Figure 2. Effects of 8b-13 on FGF receptor-mediated activation of Akt and mitogen-activated protein kinases. Starved human umbilical vein endothelial cells were pretreated with increasing concentrations of $8 \mathrm{~b}-13$ peptide $(1,5,25$ and $125 \mathrm{nM})$ for 5 min prior to stimulation with $20 \mathrm{ng} / \mathrm{ml} \mathrm{FGF8b}$ for $10 \mathrm{~min}$. Control cells did not receive FGF8b or 8b-13. The phosphorylated levels of FRS2a, Erk1/2, p38, JNK, and Akt were assessed using western blot analysis. Data are expressed as the mean \pm standard deviation. Experiments were performed in triplicate. ${ }^{~} \mathrm{P}<0.05,{ }^{\# \# \#} \mathrm{P}<0.001$ vs. control group; ${ }^{*} \mathrm{P}<0.05,{ }^{* *} \mathrm{P}<0.01,{ }^{* * *} \mathrm{P}<0.001$ vs. FGF8b alone group. FGF, fibroblast growth factor; FRS, fibroblast growth factor receptor substrate; Erk, extracellular signal-regulated kinase; JNK, c-Jun N-terminal kinase; p-, phosphorylated.

curve 65 to $95^{\circ} \mathrm{C}$ (increment $0.5^{\circ} \mathrm{C}$ ) for $5 \mathrm{sec}$. Finally, the relative changes in gene expression determined from real-time quantitative PCR experiments were calculated using the $2^{-\Delta \Delta C q}$ method (10).

Statistical analysis. The statistical significance of differences between groups was assessed by one-way analysis of variance, followed by a post hoc Tukey test for multiple comparisons. The Student's t-test was used to assess the difference between two groups. Data are expressed as the mean \pm standard deviation, and $\mathrm{P}<0.05$ was considered to indicate a statistically significant difference. The analysis was performed using GraphPad Prism software version 5.01 (GraphPad Software, Inc., La Jolla, CA, USA).

\section{Results}

8b-13 peptide suppresses FGF8b-induced HUVEC proliferation. The effects of the synthetic $8 \mathrm{~b}-13$ peptide on the FGF8b-induced proliferation of HUVECs were examined using the MTT method. 8b-13 inhibited FGF8b-triggered cellular proliferation in a dose-dependent manner, with the inhibition rate rising to $90 \%$ at a concentration of $125 \mathrm{nM}$ (Fig. 1A). Notably, 8b-13 alone had little effect on HUVEC proliferation.

In order to explore the effects of $8 b-13$ on cell cycle progression in FGF8b-stimulated HUVECs, PI staining combined with flow cytometry was used. FGF8b increased the percentage of cells at $\mathrm{S}$ phase from $23.44 \pm 0.85 \%$ to 
A

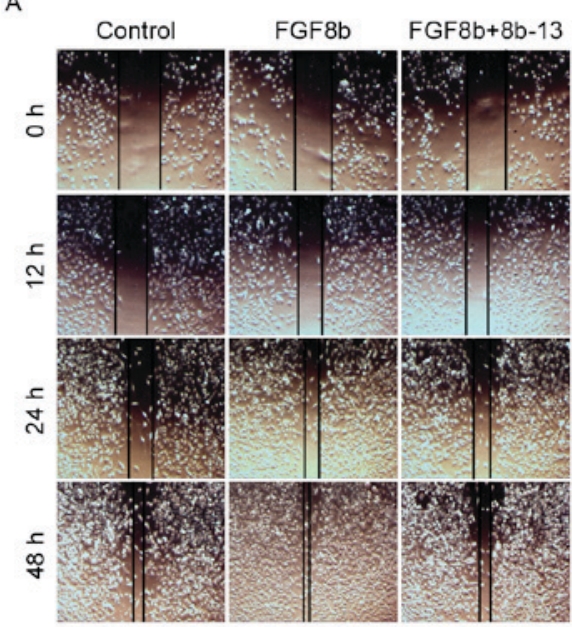

B

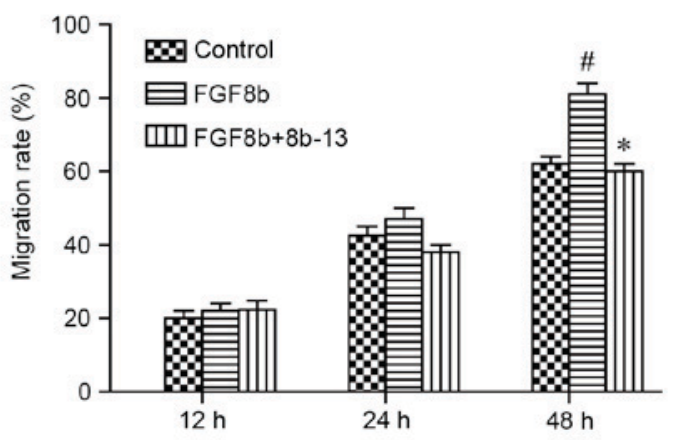

Figure 3. Effects of 8b-13 on FGF8b-stimulated human umbilical vein endothelial cell migration. Cells starved in DMEM containing $0.4 \%$ FBS were treated with FGF8b or FGF8b plus 8b-13 (25 nM) for 12, 24 or 48 h. Control cells did not receive FGF8b or 8b-13. Cellular migration was examined by scratch wound healing assay under a microscope (magnification, x100). (A) Graphic representation of the wound closure showing changes in the wound distance. (B) Migration rate was evaluated by measuring the remaining scratch distance, and is expressed as a percentage of the initial scratch distance. Data are expressed as the mean \pm standard deviation. Experiments were performed in triplicate. ${ }^{\prime \prime} \mathrm{P}<0.05$ vs. control group; ${ }^{~} \mathrm{P}<0.05 \mathrm{vs}$. FGF8b alone group. FGF, fibroblast growth factor.

$33.89 \pm 0.68 \%$, and reduced the percentage of cells at $\mathrm{G}_{0} / \mathrm{G}_{1}$ phase from $72.00 \pm 0.87 \%$ to $60.65 \pm 1.12 \%$. The addition of 8b-13 to FGF8b-stimulated cells appeared to counteract the effects of FGF8b on the cell cycle, as it decreased the percentage of cells at S-phase and increased the percentage of cells at $\mathrm{G}_{0} / \mathrm{G}_{1}$ phase (Fig. 1B).

To explore the mechanism underlying the inhibitory actions of $8 b-13$ on the FGF8b-induced progression from $G_{0} / G_{1}$ to $\mathrm{S}$ phase, the effects of $8 \mathrm{~b}-13$ on the expression of cyclin D1 were analyzed. Cyclin D1 has been demonstrated to promote the $\mathrm{G}_{1} / \mathrm{S}$ cell cycle transition (11). As presented in Fig. 1C, 8b-13 downregulated the expression of cyclin D1, which was enhanced by FGF8b stimulation. These results suggested that the decreased cyclin D1 expression may partly contribute to the $\mathrm{G}_{0} / \mathrm{G}_{1}$ phase arrest triggered by $8 \mathrm{~b}-13$ administration.

8b-13 peptide blocks FGFR signaling cascades. FGF8b exerts autocrine and paracrine effects by acting through its receptor, FGFR. It has previously been reported that the docking protein FRS2 $\alpha$ can directly interact with the activated FGFR and mediate the downstream Ras-mitogen-activated protein kinase (MAPK) and phosphatidylinositol-4,5-bisphosphate 3-kinase (PI3K)-Akt cascades, which are essential for cellular proliferation and survival $(12,13)$. The present study investigated the effects of $8 b-13$ on the FGF8b-induced activation of FRS2 $\alpha$ and its downstream cascades. Pretreatment with $8 b-13$ significantly reduced the phosphorylation levels of FRS2 $\alpha$, Erk1/2, p38, JNK and Akt, which were enhanced by FGF8b (Fig. 2). These results suggested that $8 \mathrm{~b}-13$ may inhibit the proliferation of HUVECs via preventing the activation of FRS2 $\alpha$ and its downstream pathways; the PI3K-Akt cascade appeared to be markedly affected by $8 \mathrm{~b}-13$, as suggested by the considerable decrease in FGF8b-stimulated Akt phosphorylation levels (Fig. 2).

8b-13 peptide inhibits HUVEC migration. The effects of $8 b-13$ on the migratory ability of HUVECs were evaluated using an in vitro scratch assay. Images taken at various post-scratch time points revealed complete wound closure within $48 \mathrm{~h}$ in FGF8b-treated cells; however, only partial closure was achieved within the same time in cells treated with $8 \mathrm{~b}-13$ (Fig. 3A and B). Analysis of the migration distance demonstrated that the increase in migration rate triggered by FGF8b was significantly reduced by treatment with 8b-13 (Fig. 3B).

Previous studies have revealed that the activation of STAT5 is essential for the FGF8b-induced migration of vascular endothelial cells $(14,15)$. The present study assessed the effect of $8 \mathrm{~b}-13$ on STAT5 activation using western blot analysis. The results revealed that FGF8b-induced phosphorylation of STAT5 was reduced by $8 \mathrm{~b}-13$ in a dose-dependent manner. Therefore, it may be hypothesized that $8 \mathrm{~b}-13$ exhibits antiangiogenic potential, executed via inhibiting FGF8b-induced STAT5 activation (Fig. 4).

8b-13 peptide decreases the expression of $U P A, V E G F$ and $M M P 9$. Proangiogenic factors, including uPA, VEGF and MMPs, have critical roles in various angiogenic stages. RT-qPCR was used to investigate the influence of $8 b-13$ on the expression levels of UPA, VEGF and MMP9. FGF8b increased the mRNA expression levels of uPA, VEGF and MMP9, whereas treatment with $8 \mathrm{~b}-13$ significantly decreased the mRNA expression levels of these genes (Fig. 5). These results suggested that $8 \mathrm{~b}-13$ downregulation of angiogenic factors may contribute to the antiangiogenic potential of $8 b-13$.

\section{Discussion}

Angiogenesis, which refers to the formation of new blood vessels, is critical for the continued growth and metastatic spread of malignant tumor cells (16). Therefore, therapeutic approaches aiming at inhibiting angiogenesis are promising in cancer treatment. The roles of FGF8b, alongside another 


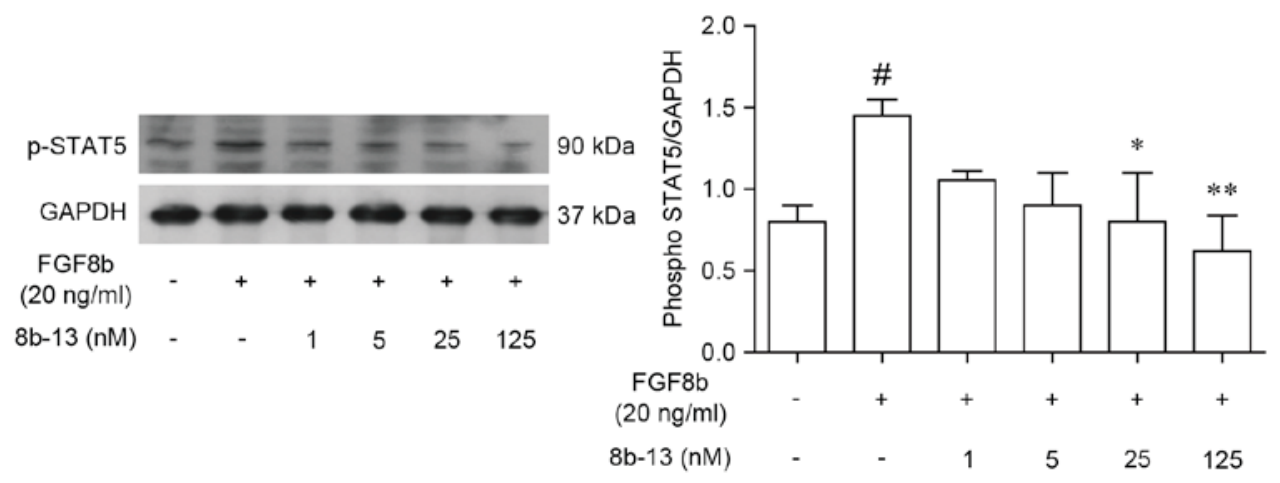

Figure 4. 8b-13 inhibits FGF8b-induced phosphorylation of STAT5. Human umbilical vein endothelial cells starved in DMEM containing $0.4 \%$ FBS were pretreated with increasing concentrations of $8 \mathrm{~b}-13$ peptide $(1,5,25$ and $125 \mathrm{nM})$ for 5 min prior to stimulation with $20 \mathrm{ng} / \mathrm{ml} \mathrm{FGF8b} \mathrm{for} 10 \mathrm{~min}$. Control cells did not receive FGF8b or 8b-13. The phosphorylated STAT5 and GAPDH were assessed by western blot analysis. Data are expressed as the mean \pm standard deviation. Experiments were performed in triplicate. ${ }^{\text {}} \mathrm{P}<0.05$ vs. control group; ${ }^{*} \mathrm{P}<0.05,{ }^{* *} \mathrm{P}<0.01$ vs. FGF8b alone group. FGF, fibroblast growth factor; STAT, signal transducer and activator of transcription.

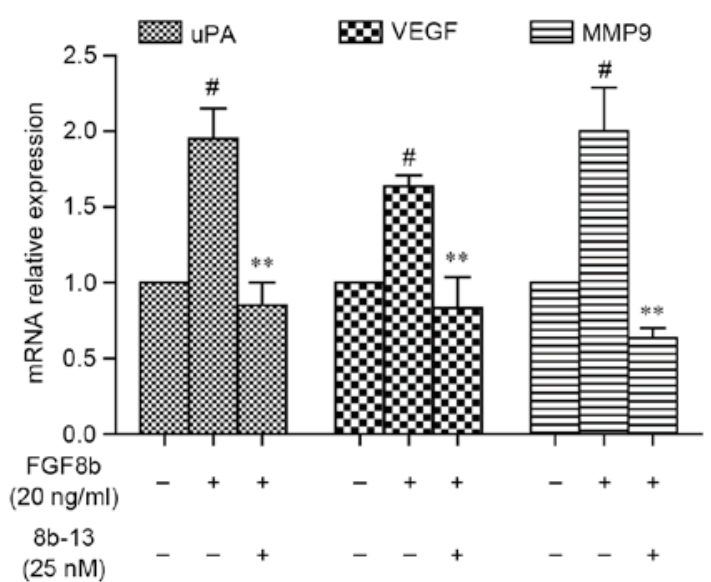

Figure 5. 8b-13 inhibits the expression of uPA, VEGF, and MMP-9. Human umbilical vein endothelial cells starved in DMEM containing $0.4 \%$ FBS were treated with $20 \mathrm{ng} / \mathrm{ml}$ FGF8b alone or $20 \mathrm{ng} / \mathrm{ml} \mathrm{FGF8b}$ together with $25 \mathrm{nM} 8 \mathrm{~b}-13$ for $48 \mathrm{~h}$. Control cells did not receive FGF8b or 8b-13. Total RNA was extracted and the relative mRNA expression levels of uPA, VEGF and MMP-9 were measured by reverse transcription-quantitative polymerase chain reaction. Data are expressed as the mean \pm standard deviation of four independent experiments. ${ }^{\#} \mathrm{P}<0.05$ vs. control group; ${ }^{* *} \mathrm{P}<0.01$ vs. FGF8b alone group. uPA, urokinase-type plasminogen activator; VEGF, vascular endothelial growth factor; MMP, matrix metalloproteinase; FGF, fibroblast growth factor.

member of the FGF family, FGF2, in tumor angiogenesis have been well documented (14,15). An FGF8b-mimicking peptide, $8 \mathrm{~b}-13$, which was designed based on the structure of the FGF8b-FGFR complex, appeared to markedly suppress the proliferation of human prostate cancer cells stimulated by endogenous and exogenous FGF8b (9). The results of the present study demonstrated that the synthetic peptide can exert inhibitory effects on the angiogenic action of FGF8b.

Since proliferation and migration of endothelial cells are critical events in angiogenic processes $(17,18)$, the present study evaluated the effects of 8b-13 on FGF8b-induced endothelial cell proliferation and migration. The results revealed that $8 \mathrm{~b}-13$ significantly inhibited the proliferation and migration of HUVECs, which were stimulated by FGF8b. It has previously been reported that $8 \mathrm{~b}-13$ may suppress prostate cancer cell proliferation induced by endogenous FGF8b (9); conversely, in the present study, the inhibitory effect of 8b-13 on the growth of HUVECs without exogenous FGF8b stimulation was insignificant. Since it has been demonstrated that almost no endogenous FGF8b is present in HUVECs (19), the absence of an 8b-13-mediated effect on HUVEC proliferation without exogenous FGF8b stimulation further confirmed the specificity of 8b-13 in targeting FGF8b.

The mechanism of the $8 b-13$-induced inhibition of HUVEC proliferation and migration was further explored. The present results revealed that $8 \mathrm{~b}-13$ counteracted the effects of FGF8b on $\mathrm{G}_{1} / \mathrm{S}$-specific cyclin D1 expression, on FGFR-mediated signaling cascades involving the kinases Erk1/2, p38, JNK, Akt and STAT5, and on the expression of the proangiogenic factors uPA, VEGF and MMP9. Cyclin D1 functions as a regulatory subunit of cyclin-dependent kinases, and regulates the transition from $G_{1}$ phase to $S$ phase, which is essential for cell cycle progression. It has previously been reported that FGF8b can induce cyclin D1 expression via the activation of PI3K-Akt and p38 MAPK pathways (20). In addition, the activation of STAT5 is involved in the regulation of cyclin D1 expression, via transactivation of the cyclin D1 promoter (21). Therefore, it may be hypothesized that $8 b-13$ can inhibit the activation of $\mathrm{p} 38$, Akt and STAT5 signaling cascades induced by FGF8b, and cause a downregulation in the $\mathrm{G}_{1} / \mathrm{S}$-specific protein cyclin D1, leading to cell cycle arrest at the $G_{0} / G_{1}$ phase and contributing to the suppression of FGF8b-induced cellular proliferation.

STAT5 activation is implicated in cellular proliferation, and appears to occur downstream of the activation of the proangiogenic factor VEGF, which is involved in FGF8b-induced cellular migration $(7,14,22)$. The present results revealed that $8 \mathrm{~b}-13$ inhibited the expression of VEGF and the phosphorylation of STAT5, which were stimulated by FGF8b. STAT5 activation can also upregulate cyclin D1 expression (21). Therefore, it may be hypothesized that the VEGF/STAT5 pathway partially mediates the inhibitory effects of $8 b-13$ on HUVEC proliferation and migration. Erk1/2 activation has been reported to enhance cellular migration, via enhancing the activity of myosin light chain kinase, causing phosphorylation 
of myosin light chains (23). Therefore, the suppression of Erk1/2 signaling cascades may be involved in the mechanism of 8b-13-mediated inhibition of cellular migration.

In conclusion, the present study demonstrated that the synthetic peptide $8 b-13$ antagonized the proangiogenic action of FGF8b by inhibiting the FGF8b-induced proliferation and migration of HUVECs. Our previous study demonstrated that 8b-13 may exhibit significant inhibitory effects on prostate cancer cell proliferation (9). These results suggested that 8b-13 may exercise antiangiogenic and antitumor effects via targeting FGF8b-mediated pathways, and may have therapeutic potential in various cancer types, which are characterized by aberrant FGF8b levels.

\section{Acknowledgements}

The present study was supported by the National Science Foundation of China (grant no. 81573334), the Natural Science Foundation of Zhejiang Province of China (grant no.LY14H310013), the Science and Technology Planning Project of Guangdong Province of China (grant no. 2015A020211017), The Opening Project of Zhejiang Provincial Top Key Discipline of Pharmaceutical Sciences, the Team Project of Natural Science Foundation of Guangdong Province of China (grant no. S2013030013315), the Undergraduate Innovation and Entrepreneurship Training Project (grant nos. 201610559036 and CX15096), and the Guangdong Provincial 'Thousand-Hundred-Ten Talent Project'.

\section{References}

1. Mattila MM, Ruohola JK, Valve EM, Tasanen MJ, Seppänen JA and Härkönen PL: FGF-8b increases angiogenic capacity and tumor growth of androgen-regulated S115 breast cancer cells. Oncogene 20: 2791-2804, 2001.

2. Valta MP, Tuomela J, Vuorikoski H, Loponen N, Väänänen RM, Pettersson K, Väänänen HK and Härkönen PL: FGF-8b induces growth and rich vascularization in an orthotopic PC-3 model of prostate cancer. J Cell Biochem 107: 769-784, 2009.

3. Ruohola JK, Viitanen TP, Valve EM, Seppänen JA, Loponen NT, Keskitalo JJ, Lakkakorpi PT and Härkönen PL: Enhanced invasion and tumor growth of fibroblast growth factor $8 \mathrm{~b}$-overexpressing MCF-7 human breast cancer cells. Cancer Res 61: 4229-4237, 2001.

4. Tuomela J, Grönroos TJ, Valta MP, Sandholm J, Schrey A, Seppänen J, Marjamäki P, Forsback S, Kinnunen I, Solin O, et al: Fast growth associated with aberrant vasculature and hypoxia in fibroblast growth factor 8b (FGF8b) over-expressing PC-3 prostate tumour xenografts. BMC Cancer 10: 596, 2010.

5. Valve E, Martikainen P, Seppänen J, Oksjoki S, Hinkka S, Anttila L, Grenman S, Klemi P and Härkönen P: Expression of fibroblast growth factor (FGF)-8 isoforms and FGF receptors in human ovarian tumors. Int J Cancer 88: 718-725, 2000.
6. Maruyama-TakahashiK,Shimada N,ImadaT,Maekawa-Tokuda Y, Ishii T, Ouchi J, Kusaka H, Miyaji H, Akinaga S, Tanaka A and Shitara K: A neutralizing anti-fibroblast growth factor (FGF) 8 monoclonal antibody shows anti-tumor activity against FGF8b-expressing LNCaP xenografts in androgen-dependent and -independent conditions. Prostate 68: 640-650, 2008.

7. Mattila MM and Härkönen PL: Role of fibroblast growth factor 8 in growth and progression of hormonal cancer. Cytokine Growth Factor Rev 18: 257-266, 2007.

8. Valta MP, Tuomela J, Bjartell A, Valve E, Väänänen HK and Härkönen P: FGF-8 is involved in bone metastasis of prostate cancer. Int J Cancer 123: 22-31, 2008.

9. Li T, Luo W, He D, Wang R, Huang Y, Zeng X, Wang W, Chen X, Gao S, Yu Y, et al: A short peptide derived from the $\mathrm{gN}$ helix domain of FGF8b suppresses the growth of human prostate cancer cells. Cancer Lett 339: 226-236, 2013.

10. Livak KJ and Schmittgen TD: Analysis of relative gene expression data using real-time quantitative PCR and the 2(-Delta Delta C(T)) method. Methods 25: 402-408, 2001.

11. Baldin V, Lukas J, Marcote MJ, Pagano M and Draetta G: Cyclin $\mathrm{D} 1$ is a nuclear protein required for cell cycle progression in G1. Genes Dev 7: 812-821, 1993.

12. Hadari Y, Gotoh N, Kouhara H, Lax I and Schlessinger J: Critical role for the docking-protein FRS2 $\alpha$ in FGF receptor-mediated signal transduction pathways. Proc Natl Acad Sci USA 98: 8578-8583, 2001

13. Ong SH, Guy GR, Hadari YR, Laks S, Gotoh N, Schlessinger J and Lax I: FRS2 proteins recruit intracellular signaling pathways by binding to diverse targets on fibroblast growth factor and nerve growth factor receptors. Mol Cell Biol 20: 979-989, 2000.

14. Yang X, Qiao D, Meyer K and Friedl A: Signal transducers and activators of transcription mediate fibroblast growth factor-induced vascular endothelial morphogenesis. Cancer Res 69: 1668-1677, 2009.

15. Yang X, Qiao D, Meyer K, Pier T, Keles S and Friedl A: Angiogenesis induced by signal transducer and activator of transcription 5A (STAT5A) is dependent on autocrine activity of proliferin. J Biol Chem 287: 6490-6502, 2012.

16. Folkman J: Role of angiogenesis in tumor growth and metastasis. Semin Oncol 29 (6 Suppl 16): S15-S18, 2002.

17. Folkman J: Angiogenesis. Annu Rev Med 57: 1-18, 2006.

18. Ucuzian AA and Greisler HP: In vitro models of angiogenesis. World J Surg 31: 654-663, 2007.

19. Antoine M, Wirz W, Tag CG, Mavituna M, Emans N, Korff T, Stoldt V, Gressner AM and Kiefer P: Expression pattern of fibroblast growth factors (FGFs), their receptors and antagonists in primary endothelial cells and vascular smooth muscle cells. Growth Factors 23: 87-95, 2005

20. Nilsson EM, Brokken LJ and Härkönen PL: Fibroblast growth factor 8 increases breast cancer cell growth by promoting cell cycle progression and by protecting against cell death. Exp Cell Res 316: 800-812, 2010.

21. Matsumura I, Kitamura T, Wakao H, Tanaka H, Hashimoto K, Albanese C, Downward J, Pestell RG and Kanakura Y: Transcriptional regulation of the cyclin D1 promoter by STAT5: Its involvement in cytokine-dependent growth of hematopoietic cells. EMBO J 18: 1367-1377, 1999.

22. Dudley AC, Thomas D, Best $J$ and Jenkins A: A VEGF/JAK2/STAT5 axis may partially mediate endothelial cell tolerance to hypoxia. Biochem J 390: 427-436, 2005.

23. Klemke RL, Cai S, Giannini AL, Gallagher PJ, de Lanerolle P and Cheresh DA: Regulation of cell motility by mitogen-activated protein kinase. J Cell Biol 137: 481-492, 1997. 